\title{
A novel biofarm technology to monitor and quantify oestrus cervix morphology in dairy cows
}

\author{
Akbar Nikkhah \\ Department of Animal Sciences, University of Zanjan, Zanjan, Iran. \\ Email: nikkhah@znu.ac.ir
}

Received 14 September 2011; revised 24 October 2011; accepted 18 November 2011.

\begin{abstract}
Increased cow productivity in the last few decades has depressed fertility and reproductive efficiency. Optimum uterus health and accurate true estrus detection have thus been greatly elusive on farm. The objective was to quantify cow cervix morphology dur-

management tool (e.g., \$US 200 - 500 for the monitoring apparatus and computer software) to quantify cow cervix morphology. The novel biofarm technology holds promises for cohort uses with farm individuals visually detecting estrus. Future research on further quantification of the reproductive tract physiology and health is required.
\end{abstract} ing proestrus (PE), standing estrus (SE), diestrus (DE) and metestrus (ME) phases of the oestrus cycle using a novel biofarm technology. The cervical tissue was videotaped with an apparatus in 4 Holstein cows (50 days in milk, 31 kg milk yield, $670 \mathrm{~kg} \mathrm{BW)} \mathrm{on} \mathrm{multi-}$ ple estrus and non-estrus phases (per treatment day $n$ $=8$ ). The videotaping apparatus had $45 \mathrm{~cm}$ length and $2.7 \mathrm{~cm}$ diameter, with internal electrical settings, external polyvinyl cover, front lights, and terminal wires for computer connection. The recordings were processed in a laptop computer installed with an image processing software. Cervix's central positioning, motility, mucosal secretions, and clarity in the captured images were scored each on a 5-scale basis. The score of 1 represented highly central, very stable, highly mucosal, and discrete cervices. The score of 5 described entirely non-central, unstable, non-mucosal, and inseparable cervices. Results verified that cervix was significantly $(P<0.01)$ more discrete, more mucosal, more central, and more stable on standing estrus days than on non-estrus days. A significant differential order $(P<0.01)$ was found for SE $>$ PE $>$ DE $>$ ME for an increased cervix distinctness (1.00, 1.20, $3.10,3.62)$, central placement $(1.13,1.50,3.73,4.15)$, stability (decreased motility) $(1.00,1.50,2.58,4.33)$, and mucosal secretions $(1.00,1.50,3.88,4.13)$, respectively. Rectal temperature (RT) was similar among $\mathrm{ME}, \mathrm{DE}, \mathrm{PE}$ and $\mathrm{SE}$ phases, respectively $\left(38.66^{\circ} \mathrm{C}\right.$, $38.33^{\circ} \mathrm{C}, 38.58^{\circ} \mathrm{C}$, and $38.83^{\circ} \mathrm{C} \pm 0.22^{\circ} \mathrm{C}$ ). Regression analysis showed minor relations between $\mathrm{RT}$ and cervix morphology changes. Findings verify the on-farm feasibility of the novel technology as a cost-effective
Keywords: Biofarm; Cervix; Morphology; Physiology; Technology

\section{INTRODUCTION}

Development of innovative and economical farm technologies is required for timely improvements in dairy cow reproduction efficiency. Simultaneous betterment in production and reproduction has been a global challenge $[1,2]$. The commonly accepted calving interval goal is about 12 - 13 months that could not necessarily be optimal [3,4]. To accomplish this goal, physiological and environmental stresses must be alleviated [1,5]. Increase metabolic pressure of early lactation compromises the capability of artificial insemination (AI) in on-time breeding and optimizing conception rate [6,7]. Such compromised reproduction efficiency is mainly attributed to failures in accurate estrus detection and on-time AI [6-8].

Transitory, short, and silent oestrus cycles are a practical challenge in true estrus detection and timely monitoring of cow reproduction behavior. For each true estrus not detected on-time, cow pregnancy is postponed by an average of 21 days. As a result, open days and calving interval will elongate, which will cost major financial and time losses $[1,9,10]$. As such, several methods have been developed to improve heat detection accuracy. Visual observation and tail painting [11], physical activity recordings with pedometers [12], perineal odors detection by electronic noses [13], and milk progesterone changes [14] are among main methods. However, these methods are rather expensive, laborious, or overly technical. Also, utilizing only a single method will not guar- 
antee optimal heat detection and conception rate. Therefore, development of low-price and accurate methods for complementary uses (to visual observation) is required. A main objective was to verify a novel farm technology to quantify and compare cervix morphology during proestrus, estrus, diestrus and metestrus phases of the oestrus cycle in early lactation Holstein cows. Another objective was to compare cervix morphology on standing estrus vs non-etsrus days. These were to establish and further most recent findings [15].

\section{MATERIALS AND METHODS}

\subsection{Cow Management and Experimental Design}

This study was conducted at the Dairy Facilities of the University of Zanjan's Research Farm (Zanjan, Iran) during November of 2009. All experimental procedures and animal management were in accordance with the guidelines of the Iranian Council of Animal Care [16]. The dairy farm had a total of 190 Holstein cattle including 50 milking cows. Cows were milked 3 times daily at 05:00, 13:00, and 21:00 h. Alfalfa hay and a barley grain based concentrate were delivered 3 and 4 times daily, respectively. Trained farm staff routinely detected estrus expression. Cows were artificially inseminated 12-h after the observance of standing-estrus signs. The standingestrus occurred when a cow was prepared to be mounted by another cow. The herd had a voluntary postpartum interval of 50 days, calving to pregnancy interval of 134 days, calving to first breeding interval of 90 days, calving interval of 13.8 months, milking days of 305, first breeding conception rate of $50 \%$, and overall conception rate of $56 \%$. Pregnancy test was conducted by rectal palpation. For the purpose of the study, 4 early lactation Holstein cows (averaging 50 days in milk, $31 \mathrm{~kg}$ milk yield, $670 \mathrm{~kg} \mathrm{BW}$ ) were monitored for cervix morphology changes during standing-estrus (SE), proestrus (PE), diestrus (DE) and metestrus (ME) phases of the cow oestrus cycle. The experimental design was a split-plot with cow as the main plot ( $n=8$ per treatment day). Rectal temperature (RT) was recorded daily for all cows.

\subsection{Technology Description and Cervix Morphology Quantification}

Daily and during PE, SE, DE, and ME phases of the cow oestrus cycle, cervix area was videotaped using a manufactured apparatus designed for monitoring cervical regions (Figure 1). The apparatus had a round shape with $45 \mathrm{~cm}$ length and $2.7 \mathrm{~cm}$ diameter with internal electrical settings and an external polyvinyl cover. The apparatus was equipped with front lights and terminal electrical wires (Figure 1). The apparatus was connected to a laptop computer installed with a recording software capable of capturing images of interest (Figure 2). The images captured were visually scored for 1) distinctness, 2) motility, 3) positioning, and 4) secretions of the cervix on a 5-score scale (Figure 3). The score of 1 represented fully 1) distinct, 2) static, 3) central-stable, and 4) mucosal cervices. The score of 2,3 , and 4 respectively were mostly, moderately, and slightly 1) distinct, 2) static, 3) centralstable, and 4) mucosal cervices. The score of 5 represented fully 1) unseparate, 2) moving, 3) noncentral, and 4) non-mucosal cervices [15].

\subsection{Statistical Analysis}

Data were analyzed using both parametric and non-parametric approaches of SAS programs [17]. Due to the similar outcomes of the two statistical methods, to provide accurate standard variations and ease numerical data interpretation, outputs of variance analysis were presented. Analysis of variance was conducted with two models. The first model included the four different phases of the oestrus cycle. The other model had either standing-estrus or non-estrus days. In the latter model, the estrus phase represented standing-estrus day and a preceding day expressing other estrus signs. The non- estrus phase score was the average of cervix morphology scores in the remaining 19 days of the oestrus cycle. In both models, cow was the main plot within which oestrus phases morphologies were compared. The split-plot statistical models included fixed oestrus phase effect, and cow within phase plus residuals random effects. The homogeneity of error variances was ensured using Proc Univariate of the SAS program [17]. The PROC REG procedure was utilized to regress rectal temperature changes during the four oestrus phases against their cervix morphology changes. The $P$-values $<0.05$ were declared as biosignificant.

\section{RESULTS AND DISCUSSION}

This study verified quantitative capability of a novel inexpensive farm technology to monitor cervix morphology in different oestrus phases in early lactation dairy cows. The cervix was significantly $(P<0.01)$ more split

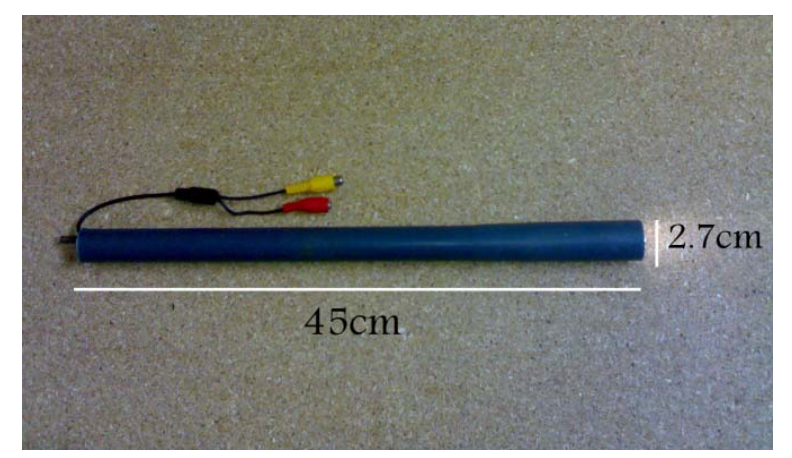

Figure 1. The cervix-monitoring apparatus with $45 \mathrm{~cm}$ length and $2.7 \mathrm{~cm}$ diameter. 


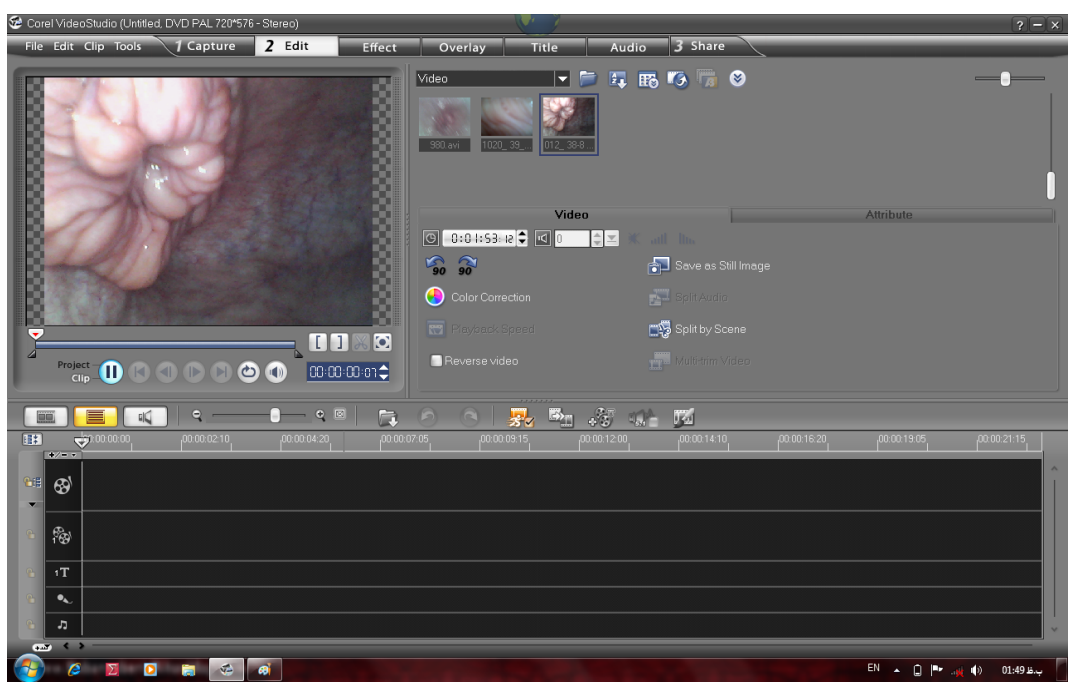

Figure 2. Cervical tissues image capturing and processing using the software installed in the computer on-farm, connected to the apparatus shown in Figure 1.

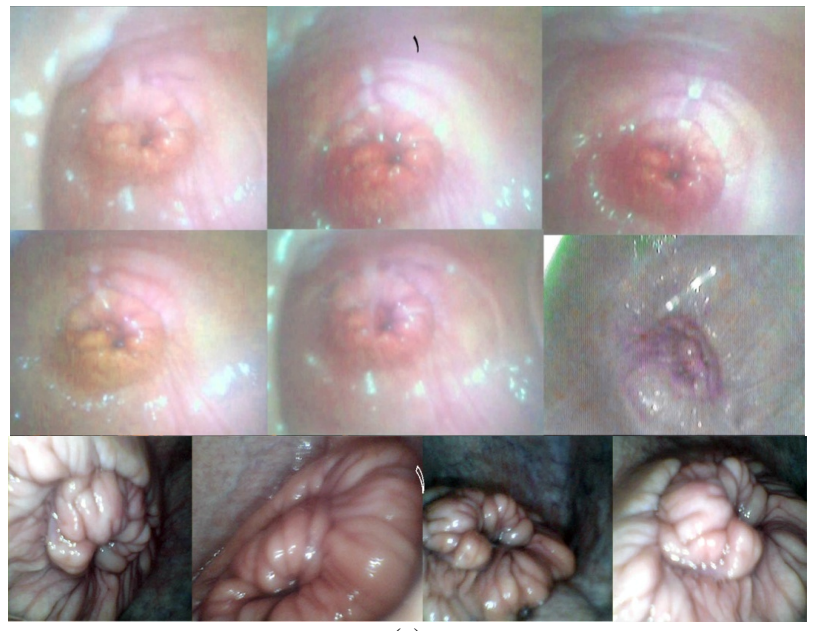

(a)

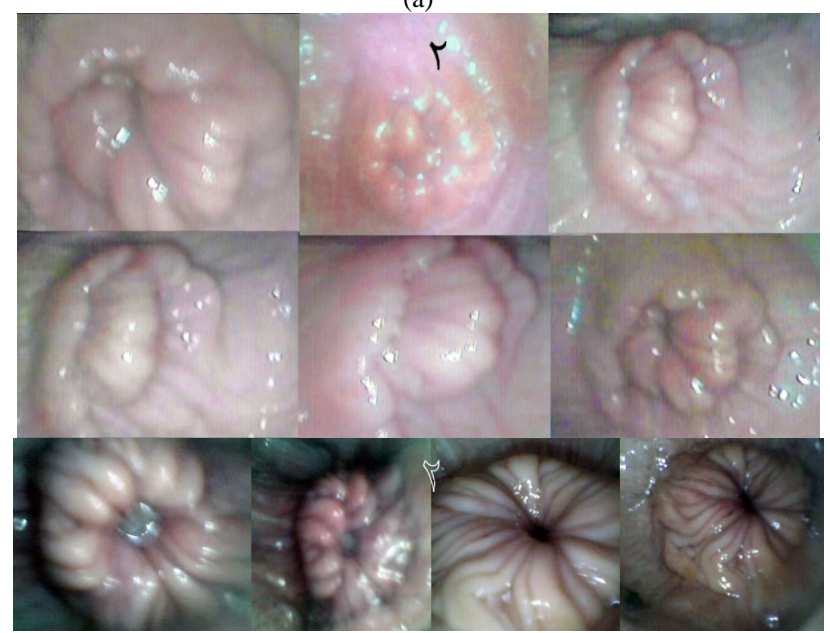

(b)

Figure 3. Cervix morphology on standing-estrus ((a), scores 1 - 2) and non-estrus ((b), scores 3 - 5) days. Each square in the top collection corresponds to its matching image in the bottom collection. 
from its surrounding tissue ( 1 vs 3 ), more stable (1.45 vs 2.82 ), more central (1.08 vs 3.63), and more mucosal (1.13 vs 3.7) on SE days than on non-estrus days (Table 1). On SE days, cervices were more visible, and rigidly positioned in the central end of vagina. On non-estrus days, however, cervices were unstable and barely separable from their surrounding regions (Figure 3 ). These findings demonstrate and verify the feasibility of applying the cost-effective technology in characterizing estrus and non-estrus cervix morphology. The four phases of the oestrus cycle including PE, SE, DS and ME exhibited significantly different cervix morphology (Table 2). Significant differential orders $(P<0.01)$ were found for SE $>\mathrm{PE}>\mathrm{DE}>\mathrm{ME}$ for greater cervix distinctness (1.00, 1.20 , 3.10, 3.62), central placement $(1.13,1.50,3.73$, $4.15)$, stability (i.e., decreased motility) $(1.00,1.50,2.58$, $4.33)$, and mucosal secretions $(1.00,1.50,3.88,4.13)$, respectively. Rectal temperature was, however, similar for $\mathrm{ME}, \mathrm{DE}, \mathrm{PE}$ and $\mathrm{SE}$ phases, respectively $\left(38.66^{\circ} \mathrm{C}\right.$, $38.33^{\circ} \mathrm{C}, 38.58^{\circ} \mathrm{C}$, and $38.83^{\circ} \mathrm{C} \pm 0.22^{\circ} \mathrm{C} ; P=0.51$ ). These data suggest that the greatest differences in cervix morphology occur in SE vs ME phases. These phases may thus be feasibly marked for morphology monitoring. Regression analysis showed only minor relations between cervix morphology and RT $(P>0.20)$. An exception was a tendency for a relationship between changes in cervix central placement $(\mathrm{Y})$ and that in RT $(\mathrm{X})$ during ME vs SE $(P=0.07)(Y=3.34-1.9 X)$. The most regression data do not suggest meaningful biological relationships $(P>0.20)$. Nonetheless, considering some rela- tion between RT and cervix positioning, and the highly different cervix morphology in ME vs SE phases, further research is required to quantitatively determine possible biological relationships.

Standing-estrus occurs when a cow is behaviorally prepared to be mounted by another cow. Usually, cows are artificially inseminated 12 - $15 \mathrm{~h}$ after SE observance. The SE is expressed following a surge in estrogen secretion that is reflected in morphologically altered tissues of the reproductive tract $[4,8]$. Thus, delays in detection of estrus signs can change the lactation curve shape. As a result, economical losses will occur $[3,18]$. By aiding to more accurately detect estrus signs, the technology developed in the current study can minimize such losses [19]. Moreover, a major number of repeat-breeder cows are those with repeated errors in estrus detection [7,9]. The different cervix morphologies between SE and nonestrus days suggest that the technology may be utilized with visual SE detectors for a more efficient AI and improved conception rate. Furthermore, as frequently happens, human estrus detectors, even if well experienced, are likely to make errors in true estrus detection, especially when multiple cows appear to be in estrus $[15,20]$. In such circumstances, the present methodology can be used to ensure that estrus cows are properly diagnosed for on-time breeding. Because of its uncomplicated nature, farm employees with brief training can proficiently utilize the technology. With only a computer, the inexpensive settings (e.g., \$US 200 - 500) can be utilized by even very small holders. Future research on additional

Table 1. Quantitative assessment of cervical morphology parameters on standing-estrus and non-estrus days using the cervix-monitoring technology ${ }^{1}$.

\begin{tabular}{lcccc}
\hline Parameter & Standing-estrus days & Non-estrus days & SEM & $P$-value \\
\hline Cervix distinctness & 1.0 & 3.0 & 0.03 & $<.01$ \\
Cervix motility & 1.45 & 2.82 & 0.04 & $<0.01$ \\
Cervix positioning & 1.08 & 3.63 & 0.07 & $<.01$ \\
Cervix secretions & 1.13 & 3.70 & 0.09 & $<0.01$ \\
\hline
\end{tabular}

${ }^{1}$ Cervix distinctness, motility, positioning, and secretions were scored each on a 5-point scale basis. Score of 1 described highly distinct (from surrounding), fully central, fully stable and static, and highly mucosal cervices; and score of 5 was entirely the other way.

Table 2. Quantitative assessment of cervical morphology parameters in different phases of the oestrus cycle with the cervix-monitoring technology ${ }^{1}$.

\begin{tabular}{lcccccc}
\hline Parameter & Proestrus & Estrus & Diestrus & Metestrus & SEM & $P$-value \\
\hline Cervix distinctness & $1.20^{\mathrm{c}}$ & $1.00^{\mathrm{c}}$ & $3.10^{\mathrm{b}}$ & $3.62^{\mathrm{a}}$ & 0.11 & $<0.01$ \\
Cervix motility & $1.50^{\mathrm{c}}$ & $1.00^{\mathrm{d}}$ & $2.58^{\mathrm{b}}$ & $4.33^{\mathrm{a}}$ & 0.15 & $<0.01$ \\
Cervix positioning & $1.50^{\mathrm{c}}$ & $1.13^{\mathrm{d}}$ & $3.73^{\mathrm{b}}$ & $4.15^{\mathrm{a}}$ & 0.12 & $<0.01$ \\
Cervix secretions & $1.50^{\mathrm{c}}$ & $1.00^{\mathrm{d}}$ & $3.88^{\mathrm{b}}$ & $4.13^{\mathrm{a}}$ & 0.08 & $<0.01$ \\
\hline
\end{tabular}

${ }^{\text {abcd }}$ Means with different superscripts differ significantly. ${ }^{1}$ Cervix distinctness, motility, positioning, and secretions were scored each on a 5-point scale basis. Score of 1 described highly distinct (from surrounding), fully central, fully stable and static, and highly mucosal cervices; and score of 5 was entirely the other way. 
specific physiological and health aspects of the reproductive tract is required to expand the on-farm applications of the current farm technology.

\section{CONCLUSIONS}

A low-price biofarm technology was developed to monitor and quantify cervix morphology in dairy cows. Cervical regions were videotaped during multiple proestrus (PE), standing-estrus (SE), diestrus (DE), and metestrus (ME) phases in early lactation Holstein cows using an apparatus that was connected to a computer program installed with an image processing software. Cervices were significantly more discrete, more central, more mucosal, and more stable on SE days than on non-estrus days. Significant differential orders were found for SE $>$ PE $>$ $\mathrm{DE}>\mathrm{ME}$ for greater cervix distinctness, central positioning, stability, and mucosal secretions. Rectal temperature was similar among different phases. A tendency for a relation between cervix positioning with RT was found. Findings demonstrate the feasibility of the novel biofarm technology in quantitative monitoring of cervix morphology. Future research on further applications of the technology in reproductive tract physiology and health monitoring is required.

\section{ACKNOWLEDGEMENTS}

The Ministry of Science, Research and Technology (Tehran, Iran) and University of Zanjan (Zanjan, Iran) are thankfully acknowledged for research and farm facilities. Dairy Farm employees are thanked for diligent cooperation and time.

\section{REFERENCES}

[1] Moore, K. and Thatcher, W.W. (2006) Major advances associated with reproduction in dairy cattle. Journal of Dairy Science, 89, 1254-1266.

doi:10.3168/jds.S0022-0302(06)72194-4

[2] Studer, E. (1998) A veterinary perspective of on-farm evaluation of nutrition and reproduction. Journal of Dairy Science, 81, 872-876. doi:10.3168/jds.S0022-0302(98)75645-0

[3] Norman, H.D., Wright, J.R., Hubbard, S.M., Miller, R.H. and Hutchison, J.L. (2009) Reproductive status of Holstein and Jersey cows in the United States. Journal of Dairy Science, 92, 3517-3528. doi:10.3168/jds.2008-1768

[4] Stransberg, E. and Oltenacu, P.L. (1989) Economic consequences of different calving intervals. Acta Agriculturce Scandinavica, 39, 407-420.

[5] Jordan, E.R. (2003) Effects of heat stress on reproduction. Journal of Dairy Science, 86, 104-E114. doi:10.3168/jds.S0022-0302(03)74043-0

[6] Lima, F.S., De Vries, A., Risco, C.A., Santos, J.E.P. and Thatcher, W.E. (2010) Economic comparison of natural service and timed artificial insemination breeding programs in dairy cattle. Journal of Dairy Science, 93, 44044413. doi:10.3168/jds.2009-2789

[7] Senger, P.L. (1994) The estrus detection problem: new concepts, technologies, and possibilities. Journal of Dairy Science, 77, 2745-2753. doi:10.3168/jds.S0022-0302(94)77217-9

[8] Redden, K.D., Kennedy, A.D., Ingalls, J.R. and Gilson, T.L. (1993) Detection of estrus by radiotelemetric monitoring of vaginal and ear skin temperature and pedometer measurements of activity. Journal of Dairy Science, 76, 713-721. doi:10.3168/jds.S0022-0302(93)77394-4

[9] Barr, H.L. (1975) Influence of estrus detection on days open in dairy herds. Journal of Dairy Science, 58, 246247. doi:10.3168/jds.S0022-0302(75)84554-1

[10] Holmann, F.J., Shumway, C.R., Blake, R.W., Schwart, R.B. and Sudweeks, E.M. (1984) Economic value of days open for Holstein cows of alternative milk yields with varying calving intervals. Journal of Dairy Science, 67, 636-643. doi:10.3168/jds.S0022-0302(84)81349-1

[11] Xu, Z.Z., McKnight, D.J., Vishwanath, R., Pitt, C.J. and Burton, L.J. (1998) Estrus detection using radiotelemetry or visual observation and tail painting for dairy cows on pasture. Journal of Dairy Science, 81, 2890-2896. doi:10.3168/jds.S0022-0302(98)75849-7

[12] Lovendahl, P. and Chagunda, M.G.G. (2010) On the use of physical activity monitoring for estrus detection in dairy cows. Journal of Dairy Science, 93, 249-259. doi:10.3168/jds.2008-1721

[13] Lane, A.J. P. and Wathes, D.C. (1998) An electronic nose to detect changes in perineal odors associated with estrus in the cow. Journal of Dairy Science, 81, 2145-2150. doi:10.3168/jds.S0022-0302(98)75791-1

[14] Moore, A.S. and Spahr, S.L. (1991) Activity monitoring and an enzyme immunoassay for milk progesterone to aid in the detection of estrus. Journal of Dairy Science, 74, 3857-3862. doi:10.3168/jds.S0022-0302(91)78578-0

[15] Nikkhah, A., Karimzadeh, S.M. and Amanloo, H. (2010) Designing, manufacturing and validating a cervix-monitoring technology for optimum estrus detection and reproduction. Iranian Society of Animal Science Proceedings, Pardis, Karaj.

[16] Iranian Council of Animal Care. (1995) Guide to the Care and Use of Experimental Animals, vol. 1. Isfahan University of Technology, Isfahan.

[17] SAS User's Guide. (2003) Version 9.1. Edition. SAS Institute Inc., Cary.

[18] De Vries, A. (2006) Economic value of pregnancy in dairy cattle. Journal of Dairy Science, 89, 3876-3885. doi:10.3168/jds.S0022-0302(06)72430-4

[19] Olynk, N.J. and Wolf, C.A. (2008) Economic analysis of reproductive management strategies on US commercial dairy farms. Journal of Dairy Science, 91, 4082-4091. doi:10.3168/jds.2007-0858

[20] Williams, W.F., Yver, D.R. and Gross, T.S. (1981) Comparison of estrus detection techniques in dairy heifers. Journal of Dairy Science, 64, 1738-1741. doi:10.3168/jds.S0022-0302(81)82757-9 